\title{
Espiritualidade e decisão de compra no mercado de planos de saúde
}

\author{
Spirituality and purchase decision in health insurance market
}

\author{
Lucas Lopes Ferreira Souza ${ }^{1}$ \\ Felipe Gerhard ${ }^{2}$ \\ Francisco Roberto Pinto ${ }^{3}$
}

\begin{abstract}
Resumo
O presente trabalho objetiva analisar a influência da espiritualidade organizacional na decisão de compra de planos de saúde. Para tal, foi validada uma escala para medir a importância daespiritualidade frente a outras variáveis que impactam a decisão de compra do consumidor. Ademais, analisou-se a espiritualidade dos entrevistados com relação aos construtos encontrados na pesquisa. Com o intuito de se alcançar os objetivos do estudo, empreendeu-se uma pesquisa descritiva, de natureza quantitativa, cujos dados foram obtidospor meio da condução de um survey. Para a análise dos dados, foram usados módulos de estatística descritiva, análise fatorial exploratória e confirmatória, e ANOVA. Como principais resultados da pesquisa, tem-se que os fatores revelados na análise são: espiritualidade organizacional, características funcionais da empresa, conexão com a empresa e preço. Observou-se que o construto espiritualidade organizacional se caracterizou como o mais importante na decisão de compra dos respondentes, tanto dos que apresentaram alto quanto baixo grau de espiritualidade.
\end{abstract}

Palavras-chave: Espiritualidade. Decisão de Compra.Planos de Saúde. Espiritualidade Organizacional. Validação de Escala.

\begin{abstract}
This study aims to analyze the influence of organizational spirituality on buying decision of health insurance plans. For this purpose, a scale is validate to measure the importance of spiritualization in relation to another constructs that affect the consumer's purchase decision. Furthermore, it is analyzed the respondents' spirituality with respect to the constructs found in the research. For that, a descriptive research with quantitative approach was undertook. As to the data extraction method,a survey was applied. For data analysis, modules of descriptive statistics, exploratory and confirmatory factor analysis and ANOVA were used. As main results of the research, the factors revealed in the analysis wereOrganization Spirituality, Functional Characteristics of Enterprise, Connection with the Company, and Price. We observed that the construct Organizational Spiritualitywas the most important factor in the buying decision of respondents, both of individuals who presented high and low degree of spirituality.
\end{abstract}

Keywords: Spirituality. Decision.Health Insurance Plans. Organization Spirituality. ScaleValidation.

\section{Introdução}

A espiritualidade é um tema que vem ganhando destaque no meio acadêmico ao longo dos últimos anos. Embora o maior volume de trabalhos esteja voltado à área organizacional, tem havido crescimento no número de pesquisas que relacionam a espiritualidade ao marketing (KALE, 2006; STANDIFER;EVAN;DONG, 2010; KUMAR et al. 2013; SHAW;THOMSON, 2013).

1 Doutorando em Administração no Programa de Pós-Graduação de Administração pela Universidade Estadual do Ceará. Brasil. Afiliação: Universidade Estadual do Ceará - UECE. Lattes: http://lattes.cnpq.br/2789006598430841 Email: Iucaslfsouza@hotmail.com

2 Doutorando em Administração no Programa de Pós-Graduação de Administração pela Universidade Estadual do Ceará. Brasil. Afiliação: Universidade Estadual do Ceará - UECE. Lattes: http://lattes.cnpq.br/0496785496091642 Email: felipegerhard.rns@gmail.com

3 Professor do Programa de Pós-Graduação em administração da Universidade Estadual do Ceará. Brasil. Afiliação: Universidade Estadual Do Ceará - UECE. Email: roberto.pinto@uece.br 
Dado que a espiritualidade cumpre papel decisivo na construção do caráter ético do indivíduo, o tema tem ganhado notoriedade ao constituir uma alternativa ao pensamento racional e materialista vigente (TORNSTAM, 1999; BARCHIFONTAINE, 2007; ULVOAS-MOAL, 2010). Apesar do avanço nas pesquisas, ainda há escassez de trabalhos voltados à temática, devido, principalmente, à falta de consenso quanto à definição adequada do conceito de espiritualidade (STANDIFER; EVANS; DONG, 2010; CHOWDHURY; FERNANDO, 2013).

Geralmente confundida com religiosidade, a espiritualidade pode ser buscada e acessada independentemente de religião. Para Emmons (1997), espiritualidade é um conceito complexo que envolve a procura por significado, por unidade e conectividade com a natureza, humanidade e transcendência. Duchon e Ashmos (2005) sintetizam a abrangência conceitual do termo espiritualidade em três ideias fundamentais, quais sejam: significado, propósito e estar conectado com os outros.

No contexto organizacional, a espiritualidade traz consigo uma orientação benéfica para o alcance do bem-estar não somente da empresa, mas de toda a sociedade. Como epifenômeno da conquista dessa dimensão, tem-se o incremento da ética, da solidariedade, da honestidade, dentre outras qualidades, tanto intraorganizacional como interorganizacional (CAVANAGH, 1999; VASCONCELOS, 2008). Da mesma forma, práticas empresariais em prol da sociedade são estimuladas, como a responsabilidade socioambiental e a conexão da missão da empresa com as necessidades da região onde ela está inserida (BARCHIFONTAINE, 2007).

Desse modo, a empresa passa a ser um elemento importante na vida da sociedade onde atua. Conceitos que destoam da lógica puramente utilitária e que transcendem o simples espectro material, como o de responsabilidade socioambiental, ética nas relações com o corpo funcional e clientes, e conexão com a sociedade (ASHMOS; DUCHON, 2000; BARCHIFONTAINE, 2007; VASCONCELOS, 2008; ULVOASMOAL, 2010), de forma geral, são aspectos que cumprem papel decisivo para a decisão de compra dos consumidores de planos de saúde (ZILBER; LAZARINI, 2008).

Observando-se o crescente interesse das pesquisas em marketing quanto às perspectivas éticas no consumo (CHOWDHURY;FERNANDO, 2012), aliado ao ineditismo da análise da relação entre espiritualidade organizacional e decisão de compra, levanta-se a seguinte questão: Qual a importância da espiritualidade organizacional na decisão de compra de consumidores de planos de saúde? Com base na questão de pesquisa delineada, o presente trabalho objetiva analisar a influência da espiritualidade organizacional na decisão de compra de planos de saúde. Para tal, foi validada uma escala para medir a importância da espiritualidade frente a outros construtos que impactam a decisão de compra do consumidor. Ademais, foi analisada a espiritualidade dos entrevistados com relação aos fatores encontrados na pesquisa.

A venda de planos de saúde é operacionalizada, basicamente, por três modalidades: planos coletivos empresariais, planos coletivos por adesão e planos individuais ou familiares (ABRAMGE, 2014); sendo esses últimos o foco deste artigo. Entretanto, é importante salientar que, no caso da contratação de planos coletivos por adesão ou empresariais, a decisão também é do consumidor, no caso o gestor da empresa.

Não obstante a venda de planos individuais represente apenas $20 \%$ do total de contratos de planos de saúde, mais de 10 milhões de pessoas são contempladas por essa modalidade (ABRAMGE, 2014; Conselho Federal de Medicina, 2014). Embora não tenha a mesma representatividade dos planos coletivos, a categoria de planos de saúde individuais é importantíssima, em termos absolutos, movimentando uma importante soma de recursos, além de representar uma saída de cobertura de saúde para milhões de pessoas (ABRAMGE, 2014; Conselho Federal de Medicina, 2014). Ademais, os planos individuais são os principais responsáveis pelo crescimento do setor $(7,4 \%)$, seguidos pelos coletivos empresariais $(4,5 \%)$ e pelo decréscimo dos planos coletivos por adesão (6,2\%) (ABRAMGE, 2015).

\section{Referencial teórico}

Nesta seção, serão abordados os principais aspectos teóricos atinentes ao objetivo de pesquisa. Dessa forma, a espiritualidade nas organizações e os fatores chaves da decisão de compra de consumidores de planos de saúde são analisados. 


\subsection{Espiritualidade nas organizações}

A espiritualidade tem recebido considerável atenção nos últimos anos (ULVOAS-MOAL, 2010), particularmente na literatura organizacional versada às relações de trabalho (STANDIFER; EVANS; DONG, 2010). Contudo, embora seja um conceito central em ciências como a psicologia e a sociologia, ainda são poucas as pesquisas sobre a influência da espiritualidade no campo de estudos do comportamento do consumidor (ZINNBAUER;PARGAMENT, 2005; ULVOAS-MOAL, 2010). O que outrora era considerado um assunto desligado do contexto organizacional, porquanto era visto como algo referente à religião $\mathrm{e}$ ao misticismo, ganhou status de imanência por ser um conceito que dá significado e razão de existir às organizações e ao trabalho das pessoas (BARCHIFONTAINE, 2007).

A espiritualidade vem ganhando notoriedade ao representar uma lógica alternativa e destoante do tradicional pensamento econômico material e racional, que considera prejudicial à eficiência empresarial a intromissão de valores transcendentais, refletidos em princípios morais e sociais (TORNSTAM, 1999; BARCHIFONTAINE, 2007; ULVOAS-MOAL, 2010). Não obstante a ascensão da temática, a escassez de estudos sobre o tema se deve, em parte, à carência de consenso sobre uma definição operacional adequada e à confusão entre os conceitos de espiritualidade e religiosidade (ZINNBAUER; PARGAMENT, 2005; STANDIFER; EVANS; DONG, 2010; CHOWDHURY; FERNANDO, 2013).

A respeito da imprecisão entre os conceitos de espiritualidade e religiosidade, é importante que seja destacado que, embora possuam elementos teóricos em comum, eles são construtos diferentes (CHOWDHURY; FERNANDO, 2013). Uma analogia interessante é evidenciada por Miller e Thoresen (2003), os quais aduzem que o campo da religião está para a espiritualidade assim como a medicina está para a saúde. Para os autores, a religiosidade pode ser considerada um conceito basilar para a construção da espiritualidade. Contudo, a espiritualidade pode ser buscada e acessada independentemente de religião.

Ao definir e delinear os conceitos de espiritualidade e religiosidade, Emmons (1997) elucida que a espiritualidade é uma ideia mais abrangente, que envolve a procura por significado, por unidade e conectividade com a natureza, humanidade e transcendência, fatores sintetizados por Duchon e Ashmos (2005) no que consideram as três necessidades espirituais fundamentais, quais sejam: significado, propósito e estar conectado com os outros. Por outro lado, segundo Emmons (1997), religião é um conjunto de dogmas que orientam a vida moral do indivíduo sob a influência da fé em ensinamentos e narrativas históricas. Tais narrativas, segundo Dollahite (1998), realçam a procura do sagrado e da moralidade, pontos nos quais os conceitos de espiritualidade e religiosidade se interceptam.

Embora as definições de Emmons (1997) estejam versadas à dimensão individual, as acepções teóricas trazidas pelo autor podem ser facilmente expandidas para se compreender a ideia de espiritualidade organizacional. No contexto da espiritualidade nas empresas, alguns conceitos cumprem papel decisivo para que essa dimensão seja alcançada. Dentre os quais, a responsabilidade socioambiental, lógica ordenada incumbida de desenvolver as ações políticas e práticas da empresa, é compreendida como a forma na qual a instituição se conecta, sem necessariamente incorrer em projetos filantrópicos, com a sociedade, inclusive com o seu corpo funcional, e com o ambiente em que está inserida (BARCHIFONTAINE, 2007; VASCONCELOS, 2008).

Outro importante fator que faculta o alcance da espiritualidade nas organizações é a ética, que mantem foco na finalidade maior de respeito à vida (BARCHIFONTAINE, 2007). Não prescindir da ética significa considerar o ser humano em sua plenitude, observando e investindo em suas dimensões física, intelectual, emocional e espiritual. O ser humano em questão não se restringe ao espectro funcional. Clientes, corpo laboral de empresas parceiras e, até mesmo, os demais indivíduos da sociedade são compreendidos e atendidos pelos valores humanos orientados pela ética organizacional (BARCHIFONTAINE, 2007).

A conexão e coesão entre empresa, funcionários e clientes também é um atributo decisivo para o alcance da espiritualidade nas organizações (BARCHIFONTAINE, 2007). A humanização e intensificação das relações do corpo funcional auxilia na manutenção do bem-estar no ambiente de trabalho, coadjuvando igualmente para a construção de uma cultura de solidariedade na empresa (CAVANAGH, 1999; BARCHIFONTAINE, 2007). A conexão, contudo, não se limita ao nível intraorganizacional, alcançando 
também o envolvimento com os clientes. Nesse caso, identificar-se com a missão e valores da empresa, bem como possuir facilidade de acesso e comunicação, são fatores que contribuem para que o cliente sinta uma forte conexão com a organização.

Como consequência da espiritualidade, atributos que contribuem para o desenvolvimento das atividades laborais no ambiente de trabalho, como a honestidade, a benevolência e a solidariedade, dentre outros, são exaltados na organização (BARCHIFONTAINE, 2007; VASCONCELOS, 2008).

Cumpre destacar, contudo, que conceitos correlatos, como cidadania corporativa, compartilhamento de riqueza e conhecimento, e promoção da saúde humana (VASCONCELOS, 2008), já estão abarcados pelos fatores detalhados acima de certa forma.

Ademais, é importante que seja feita uma ressalva quanto às congruências conceituais dentre os movimentos de espiritualidade e humanização nas empresas. A espiritualidade, para alguns autores, traz consigo uma amplitude ainda maior do que a humanização. Embora seja um avanço em relação ao pensamento econômico-materialista tradicional, a humanização das empresas não alcança a evolução nas relações que a espiritualidade atinge, seja entre empresa e corpo funcional, seja entre empresa e sociedade (ULVOAS-MOAL, 2010).

\subsection{Influência da espiritualidade na decisão de compra de planos de saúde}

O estudo de decisão de compra, em que pese ser assunto já bastante abordado, sempre levanta novas dúvidas, porque envolve fatores culturais, sociais, pessoais e psicológicos. Variação em qualquer desses aspectos pode acarretar grandes mudanças no comportamento dos consumidores (ENGEL; BLACKWELL; MINIARD, 1995), o que mantém o tema relevante.

Petchsawang e Duchon (2009) aduzem que, além das influências do contexto, a individualidade implica divergências de avaliação na decisão de compra e que, apesar do ambiente exercer grande influência nas inclinações do consumidor, há na abordagem espiritual da decisão de compra um foco marcadamente individual.

As pesquisas em marketing têm demonstrado significativo interesse na dimensão ética do consumo (VITELL, 2003), e a espiritualidade tem emergido como um importante fator, que influencia tanto a ética individual como o comportamento de compra (CHOWDHURY; FERNANDO, 2012). Com efeito, segundo Emmons (1999), espiritualidade, como tipicamente idealizada, engloba a procura por significado, por unidade, por conectividade com a natureza, humanidade e transcendência. Corroborando com o autor, Gotsis e Kortezi (2008) descrevem espiritualidade desvinculando-a de qualquer religião ou doutrina. Para eles, é um conceito universal, que suporta uma ênfase em sistemas de valores e na construção de uma comunidade que retenha elementos transcendentais. Expandindo-se a concepção de espiritualidade para delimitar o contexto empresarial, uma organização espiritualizada é aquela que possui destacados valores éticos, uma forte responsabilidade socioambiental, um tratamento distinto aos seus colaboradores e uma marcada conexão com a comunidade em que atua (ASHMOS; DUCHON, 2000). Ademais, empresas espiritualizadas são avaliadas positivamente pelos seus consumidores.

Além das questões de ordem pessoal, os fatores de mercado interferem na decisão de compra e as próprias empresas elegem alguns fatores que serão determinantes para a geração de vantagens competitivas (ZILBER; LAZARINI, 2008). Com relação às empresas de planos de saúde, os fatores proeminentes da decisão de compra de um consumidor seriam: (1) preço; (2) qualidade diferenciada; (3) reputação da marca (4) número de credenciados; (5) distribuição geográfica; (6) agilidade no atendimento; (7) disponibilidade para marcação de consultas e procedimentos; (8) facilidade de atendimento na empresa; e (9) ter um canal de comunicação fácil para discutir problemas e necessidades (ZILBER;LAZARINI, 2008). Contudo, Ashmos e Duchon (2000) sugerem novos fatores, relacionados à espiritualidade empresarial, que podem vir a se tornar características influenciadoras na tomada de decisão dos consumidores: (10) presença de valores éticos; (11) conexão entre a atividade da empresa e o bem social da comunidade; (12) importância que a empresa dá aos seus próprios empregados; (13) o sentir-se conectado com a missão da empresa; e (14) conexão entre a atividade da empresa e o bem social da comunidade. 
Para Pinto (2009), é imprescindível que a empresa moderna desenvolva características de espiritualidade para uma convivência harmônica com seus stakeholders. Considerando ser essa uma tendênciana sociedade atual, tal atitude termina por significar um diferencial a interferir na decisão de compra.

\section{Metodologia}

Para atender aos propósitos definidos, empreendeu-se uma pesquisa descritiva, de natureza quantitativa, realizada por meio de um estudo de corte transversal único, cuja consecução foi obtida pela condução de um survey (HAIRet al., 2009; MALHOTRA, 2006).

$\mathrm{O}$ instrumento de pesquisa está dividido em três seções. Primeiramente, foi construída uma escala de importância, como consta no quadro 1, cujos valores variavam de 1 a 10, elaborada e adaptada a partir das principais características observadas na escala de Zilber e Lazarini (2008). Também foram adicionados ao instrumento alguns itens referentes à escala de Ashmos e Duchon (2000) sobre espiritualidade organizacional.

Cumpre destacar que o fato do construto custos ser constituído por uma única variável observável não representa um entrave para o prosseguimento da pesquisa. A mensuração de uma variável latente com apenas uma questão não prejudica o instrumento de pesquisa, contanto que o objeto de análise seja claro e não exija grandes elucubrações por parte dos respondentes (BERGKVIST; ROSSITER, 2007). Ademais, destaca-se que a escala de Zilber e Lazarini (2008) também é composta por construtos que possuem apenas uma variável.

Quadro 1 - Variáveis da decisão de compra

\begin{tabular}{|c|c|c|c|}
\hline $\mathbf{N}^{\circ}$ & Variável & Construto & Autores \\
\hline DC.1 & Preço. & Custos & \multirow{9}{*}{$\begin{array}{l}\text { Zilber e } \\
\text { Lazarini } \\
(2008)\end{array}$} \\
\hline DC.2 & $\begin{array}{l}\text { Qualidade diferenciada da rede de credenciados (profissionais } \\
\text { de saúde, clínicas, hospitais e laboratórios). }\end{array}$ & \multirow{2}{*}{$\begin{array}{l}\text { Estratégia de } \\
\text { diferenciação }\end{array}$} & \\
\hline DC.3 & Reputação da marca. & & \\
\hline DC.4 & $\begin{array}{l}\text { O número de credenciados (profissionais de saúde, clínicas, } \\
\text { hospitais e laboratórios). }\end{array}$ & \multirow{2}{*}{$\begin{array}{l}\text { Recursos da } \\
\text { empresa }\end{array}$} & \\
\hline DC.5 & Distribuição geográfica de credenciados. & & \\
\hline DC.6 & Agilidade no atendimento na empresa. & $\begin{array}{l}\text { Agilidade nos } \\
\text { processos }\end{array}$ & \\
\hline DC.7 & Disponibilidade para marcação de consultas e procedimentos. & \multirow{3}{*}{$\begin{array}{c}\text { Atender a } \\
\text { necessidade } \\
\text { dos clientes }\end{array}$} & \\
\hline DC.8 & $\begin{array}{l}\text { Facilidade de atendimento na empresa (tecnologias de acesso e } \\
\text { comunicação). }\end{array}$ & & \\
\hline DC.9 & $\begin{array}{l}\text { Ter um canal de comunicação fácil para discutir problemas e } \\
\text { necessidades. }\end{array}$ & & \\
\hline E.1 & Presença de valores éticos. & \multirow{4}{*}{$\begin{array}{l}\text { Espiritualidade } \\
\text { organizacional }\end{array}$} & \multirow{4}{*}{$\begin{array}{l}\text { Ashmos } \\
\text { e Duchon } \\
\text { (2000) }\end{array}$} \\
\hline E.2 & A importância que a empresa dá aos seus próprios empregados. & & \\
\hline E.3 & Sentir-se conectado com a missão da empresa. & & \\
\hline E.4 & $\begin{array}{l}\text { Conexão entre o as atividades da empresa e o bem social da } \\
\text { comunidade. }\end{array}$ & & \\
\hline
\end{tabular}

Fonte: Adaptado das escalas de Zilber e Lazarini (2008) e Ashmos e Duchon (2000).

Com isso, buscou-se identificar quais variáveis eram mais importantes para a decisão de compra do consumidor. É importante ressaltar que a escala desenvolvida por Zilber e Lazarini (2008) levanta atributos da decisão de compra que, segundo os autores, seriam os mais pertinentes para a escolha de um plano de saúde. O intuito de se inserir um novo construto é aferir se ele de fato apresentará relevância frente a outros já sedimentados na literatura. 
Na segunda seção, foi inserido no instrumento de pesquisa um fator da escala de Ashmos e Duchon (2000), como evidenciado no quadro 2, a seguir, chamado pelos autores de espiritualidade interna, para aferir a espiritualidade dos respondentes.

Quadro 2 - Espiritualidade interna

\begin{tabular}{|c|l|c|c|}
\hline No $^{\circ}$ & \multicolumn{1}{|c|}{ Variáveis } & Construto & Autores \\
\cline { 1 - 2 } El.1 & Eu me sinto otimista em relação à vida. & \multirow{2}{*}{$\begin{array}{c}\text { Espiritualidade } \\
\text { Interna }\end{array}$} & $\begin{array}{c}\text { Ashmos e } \\
\text { Duchon (2000) }\end{array}$ \\
\cline { 1 - 2 } El.2 & Meus valores espirituais influenciam as escolhas que eu faço. & \\
\cline { 1 - 2 } El.3 & Eu me considero uma pessoa espiritualizada. & $\begin{array}{l}\text { Eu me importo com a saúde espiritual de meus parentes e } \\
\text { amigos. }\end{array}$ & \\
\hline
\end{tabular}

Fonte: Adaptado da escala de Ashmos e Duchon (2000).

A outra parte, destinada à caracterização dos respondentes, constava das seguintes questões sociodemográficas: gênero, renda mensal familiar, atividade profissional, faixa etária e se os respondentes possuíam plano de saúde.

A partir das escalas criadas, foram realizados dois surveys com alunos de graduação de uma universidade pública de Fortaleza. A primeira, com 106 respondentes, foi conduzida nos meses de setembro e outubro de 2013, ao passo que a segunda, realizada com 141 respondentes, foi conduzida durante o mês de março de 2014. A análise estatística foi realizada por meio do software Statistical Package for the Social Sciences (SPSS) e AMOS, no qual foram usados módulos de estatística descritiva e análise fatorial exploratória, análise fatorial confirmatória e ANOVA.

Cumpre salientar que a análise fatorial exploratória foi realizada com o intuito de conhecer quais variáveis são importantes na decisão de compra, de forma que os fatores formados evidenciassem construtos que fossem relevantes para a literatura e que tivessem importância na decisão de compra do consumidor. A análise fatorial confirmatória, por outro lado, foi utilizada para validar a escala desenvolvida. A ANOVA foi utilizada para conhecer se há diferenças entre respondentes espiritualizados e não espiritualizados com relação aos fatores formados a partir da análise fatorial exploratória.

\section{Análise dos resultados}

Nesta seção são discutidos os resultados encontrados na pesquisa. Inicialmente, será realizada a análise fatorial exploratória para se verificar o agrupamento das variáveis do estudo. Em seguida, será utilizada a análise fatorial confirmatória para validar a escala, confirmando, ou refutando os achados encontrados na etapa inicial. Por fim, será realizada uma ANOVA para se conhecer se há significância entre a diferença de variância dos respondentes espiritualizados e não espiritualizados em relação aos fatores encontrados.

\subsection{Análise fatorial exploratória}

De acordo com os resultados obtidos por meio do survey com os 106 entrevistados, verificou-se que a amostra é composta por 35 pessoas do sexo masculino (33\%) e 71 do sexo feminino (67\%). Quanto à renda, 18 pessoas (17\%) possuem renda familiar menor que dois salários mínimos, $40(37,7 \%)$ possuem renda mensal entre dois e cinco salários mínimos, 30 pesquisados $(28,3 \%)$ possuem entre cinco e dez salários mínimos e, por fim, 14 respondentes (13,2\%) possuem renda familiar mensal acima de 10 salários mínimos. No que concerne ao exercício de atividades profissionais, somente dezesseis pessoas (15,1\%) responderam que realizavam alguma atividade remunerada.

Ao se analisar a idade dos respondentes, observa-se que houve uma predominância de pessoas com faixa etária de até 20 anos, com 48 pessoas (45,3\%). Ademais, 37 pessoas $(32,9 \%)$ estão na faixa etária de 21 a 30 anos e 12 pessoas (21,85\%) têm idades superior a 30 anos. Dos respondentes, 70 indivíduos (66\%) disseram possuir plano de saúde, enquanto $36(34 \%)$ responderam que não possuíam. 
Após as estatísticas descritivas da amostra, foi realizada a análise fatorial exploratória com os dados da pesquisa. Deve-se destacar que a variável preço foi excluída da análise fatorial exploratória por ser uma característica autoexplicativa (ZILBER; LAZARINI, 2008).

Em ato contínuo, utilizando-se o método de análise dos componentes principais por meio da rotação ortogonal Varimax e o critério de autovalores superiores a um (HAIR et al., 2009), foram obtidos três fatores que, em conjunto, explicaram $65,40 \%$ da variância total. Quanto ao índice KMO $(0,834)$ e o teste de esfericidade de Bartlett $(p=0,000)$, foram alcançados valores satisfatórios. Contudo, ao se avaliar a comunalidade das variáveis, o item DC.5 $(0,404)$, "distribuição geográfica de credenciados", não alcançou o índice mínimo exigido de 0,5 (HAIR et al., 2009).

Realizando-se a retirada da questão apontada, uma nova análise fatorial foi empreendida. A nova estrutura erigida pela análise obteve indicadores satisfatórios, uma vez que se obteve um excelente índice KMO $(0,838)$, bem como um teste esfericidade de Barlett satisfatório $(p=0,000)$ (HAIR et al., 2009; COSTA, 2011). A estrutura subjacente construída pela análise fatorial agrupou as questões em três fatores, alcançando uma variância total explicada de 68,71\%.

Os três fatores resultantes da análise foram analisados de acordo com a similitude semântica apresentada por suas variáveis constituintes. Dessa forma, os construtos foram denominados de: espiritualidade organizacional, composto pelas variáveis E.1, E.2 e E.4; características funcionais da empresa, composto pelas variáveis DC.2, DC.6, DC.7 e DC.8; e, por último, o construto conexão com a empresa, que foi composto pelas variáveis DC.3, DC.8, E.3 e DC.9, conforme demonstrado na tabela 1a seguir.

Tabela 1 - Matriz de componentes rotacionada - Decisão de compra

\begin{tabular}{|c|c|c|c|c|c|}
\hline \multirow{2}{*}{\multicolumn{2}{|c|}{ Variáveis }} & \multicolumn{3}{|c|}{ Componente } & \multirow{2}{*}{ Fatores } \\
\hline & & \multirow{2}{*}{$\frac{1}{0,838}$} & \multirow[t]{2}{*}{2} & \multirow[t]{2}{*}{3} & \\
\hline E.1 & Valores éticos. & & & & \multirow{3}{*}{$\begin{array}{l}\text { Espiritualidade } \\
\text { Organizacional }\end{array}$} \\
\hline E.2 & $\begin{array}{l}\text { A importância que a empresa dá aos seus } \\
\text { próprios empregados. }\end{array}$ & \multicolumn{3}{|l|}{0,842} & \\
\hline E.4 & $\begin{array}{l}\text { A empresa faz conexão entre o seu trabalho e o } \\
\text { bem social da comunidade. }\end{array}$ & \multicolumn{3}{|l|}{0,798} & \\
\hline DC.2 & $\begin{array}{l}\text { Qualidade diferenciada da rede de credenciados } \\
\text { (profissionais de saúde, clínicas, hospitais e } \\
\text { laboratórios). }\end{array}$ & \multicolumn{3}{|c|}{0,653} & \multirow{4}{*}{$\begin{array}{l}\text { Características } \\
\text { Funcionais da } \\
\text { Empresa }\end{array}$} \\
\hline DC.6 & A agilidade no atendimento na empresa. & \multicolumn{3}{|c|}{0,811} & \\
\hline DC.7 & $\begin{array}{l}\text { Disponibilidade para marcação de consultas e } \\
\text { procedimentos. }\end{array}$ & \multicolumn{3}{|c|}{0,861} & \\
\hline DC.8 & $\begin{array}{l}\text { Facilidade de atendimento na empresa } \\
\text { (tecnologias de acesso e comunicação). }\end{array}$ & \multicolumn{3}{|c|}{0,533} & \\
\hline DC.4 & $\begin{array}{l}\text { O número de credenciados (profissionais de } \\
\text { saúde, clínicas, hospitais e laboratórios). }\end{array}$ & & & 0,659 & \multirow{4}{*}{$\begin{array}{l}\text { Conexão com a } \\
\text { Empresa }\end{array}$} \\
\hline DC.3 & A reputação da marca. & & & 0,663 & \\
\hline E.3 & Sentir-me conectado com a missão da empresa. & & & 0,745 & \\
\hline \multirow[t]{3}{*}{ DC.9 } & $\begin{array}{l}\text { Ter um canal de comunicação fácil para discutir } \\
\text { meus problemas e necessidades. }\end{array}$ & & & 0,568 & \\
\hline & Alpha de Cronbach & 0,842 & 0,835 & 0,715 & \\
\hline & Variância Explicada & $27,26 \%$ & $23,39 \%$ & $18,94 \%$ & \\
\hline
\end{tabular}

Método de Rotação: Varimax com Kaiser Normalization.

A rotação convergiu em 9 iterações.

Fonte: Autoria própria.

Como é possível constatar por meio do exame da tabela, todas as variáveis alcançaram cargas fatoriais satisfatórias, i.e., acima de 0,5 (HAIR et al., 2009). Ademais, observa-se que o construto espiritualidade 
organizacional é o mais importante da análise, porquanto explica $27,26 \%$ da variância total. Esse construto é formado por três variáveis da escala de espiritualidade organizacional, que representam um ideário permeabilizado por uma forte questão ética, versada tanto ao conceito em si como à responsabilidade com o bem-estar da sociedade e dos seus empregados. Por sua vez, o construto características funcionais da empresa caracteriza-se como o segundo fator mais importante da análise, explicando $23,39 \%$ da variância total. Essa variável latente é formada pelo agrupamento de quatro variáveis que possuem uma destacada congruência semântica versada a atributos relacionados ao desempenho das atividades operacionais de empresas de plano de saúde. Por fim, o construto conexão com a empresa explica 18,94\% da variância total. O fator é constituído por variáveis que significam, principalmente, aspectos relacionados à facilidade com a qual o cliente pode acessar a empresa.

A etapa de análise semântica das variáveis e dos construtos recém-realizados são protocolos importantes para a validade de translação da escala. Tal fase consiste em se examinar a estrutura completa da escala, observando-se as variáveis latentes que a constituem (HAIR et al., 2009; COSTA, 2011). A etapa é constituída por dois momentos: a análise do conteúdo dos itens e construtos do instrumento de pesquisa (validade de conteúdo) e o exame da forma, pertinência e representatividade do conjunto de itens do construto (validade de face) (HAIR et al., 2009; COSTA, 2011).

Observando-se a confiabilidade dos construtos, atestada pelo alpha de Cronbach, todos os construtos atingiram índices satisfatórios (HAIR et al., 2009; COSTA, 2011). O alpha do construto espiritualidade organizacional atingiu o índice de 0,842 , o fator características funcionais da empresa apresentou alpha de 0,835 , e o componente conexão com a empresa obteve um alpha de 0,715 . Tal procedimento é um importante indicador para se aferir a consistência interna dos construtos da pesquisa, ou seja, a acurácia do conjunto de itens que os constituem. Todos os resultados alcançaram valores acima de 0,7 , atestando boa confiabilidade aos construtos. A análise indicou que há homogeneidade entre as questões que compõem as variáveis latentes e a escala como um todo.

\subsection{Análise Fatorial Confirmatória e Validação de Escala}

Por conseguinte, foi realizada a análise fatorial confirmatória (AFC) para conhecer se os construtos formados são adequados para mensurar o que se propõem. Desse modo, a escala passou por um processo de validação de construto (convergente e discriminante), baseado nos procedimentos de Churchill (1979) e Costa (2011). Para essa análise foram aplicados mais 141 questionários com outros universitários da mesma instituição de ensino. Deve-se acentuar que os novos foram somados aos 106 iniciais, atingindose um total de 247 questionários. Desse modo, o perfil dos respondentes desta análise está composto por 53 homens $(21,5 \%)$ e 186 mulheres $(75,3 \%)$ e 8 missings values. Dos respondentes, 157 possuem planos de saúde $(63,6 \%)$ e 80 não possuem (32,4\%), enquanto 10 não responderam à questão. Quanto à renda familiar, 16,2\% ganham até dois salários mínimos, $26,2 \%$ ganham de dois a cinco salários mínimos e $25,8 \%$ recebem de cinco a dez salários mínimos, sendo que $15 \%$ não responderam. Outros $16,8 \%$ são de famílias que ganham mais de 10 salários mínimos. Por fim, quanto à idade, 136 dos respondentes têm até 20 anos (55,1\%), 82estão na faixa de 21 a 30 anos (33,2\%), e os demais têm idade acima de 30 anos, com 5 missings.

Para dar prosseguimento à análise, os novos 141 pesquisados foram submetidos ao teste de outliers univariado, ocasionando a retirada de 14 questionários por apresentarem valores maiores do que três desvios-padrões (HAIR et al., 2009). Desse modo, restaram 233 questionários, os quais foram utilizados para a realização da análise fatorial confirmatória. Na figura 1, a seguir, pode-se observar o modelo de mensuração com os construtos obtidos. 
Figura 1 - Modelo de mensuração dos construtos levantados na AFE

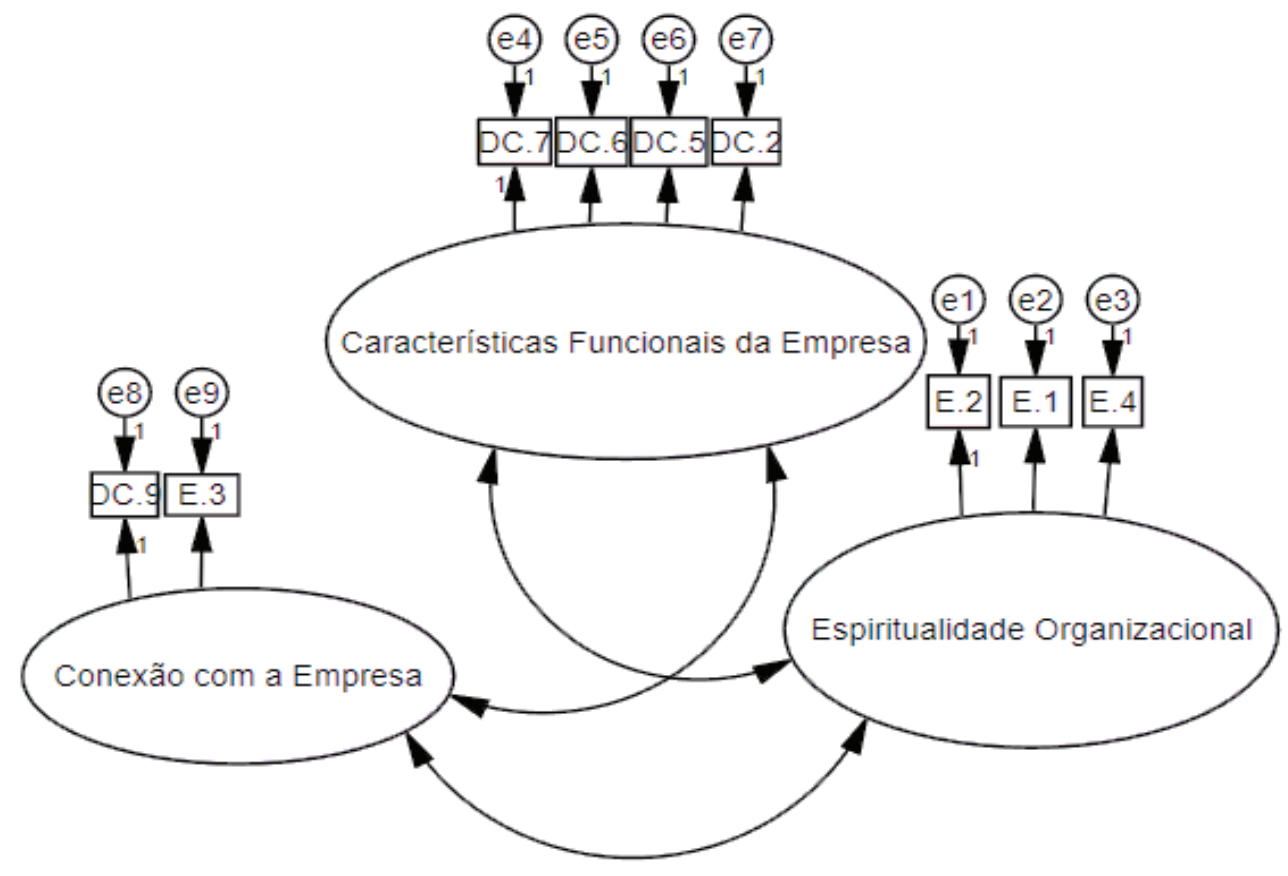

Fonte: Autoria própria.

No que concerne à validação da escala, Fornell e Larker (1981) e Garver e Mentzer (1999) indicam que a confiabilidade composta (CR) é satisfatória quando se atinge um índice maior do que 0,7 , e a variância média extraída (AVE) é maior do que 0,5 . Os dois parâmetros compõem o protocolo de validade convergente da escala. Para a validade discriminante, os mesmos autores indicam que é alcançada quando a variância extraída de cada construto é maior do que a máxima variância quadrada compartilhada (MSV) e a variância quadrada média compartilhada (ASV). Na tabela 2, a seguir, observam-se os resultados da análise convergente e discriminante.

Nota-se que foram retiradas as variáveis DC.3 e DC.4 por apresentarem baixa carga fatorial, respectivamente, 0,464 e 0,455. Dessa forma, dando prosseguimento à análise, foram encontrados os seguintes resultados para o modelo: CMIN/DF $(4,138)$; GFI $(0,916)$; CFI $(0,919)$; RMSEA $(0,116)$. Segundo Hairet al. (2009) e Byrne (2009) os valores adequados seriam: CMIN/DF abaixo de 5,00; GFI acima de 0,900; CFI acima de 0,900; e RMSEA abaixo de 0,08. Dessa forma, somente para o valor do critério estabelecido para o RMSEA não foi obtido resultado adequado. Esse índice indica a quantidade de erro de aproximação populacional numa matriz de covariância, isto é, representa de forma mais adequada quão bem um modelo se ajusta à população, não apenas à amostra utilizada para a estimação (HAIR et al., 2009). Entretanto, isto não é tão importante para o trabalho, uma vez que não se pretende analisar o modelo e suas relações causais, mas verificar se há validade convergente e discriminante.

Tabela 2 - Protocolo de validação convergente e discriminante

\begin{tabular}{l|l|l|l|l}
\hline \multicolumn{1}{c|}{ Construtos } & \multicolumn{1}{c|}{ CR } & \multicolumn{1}{c|}{ AVE } & \multicolumn{1}{c}{ MSV } & \multicolumn{1}{c}{ ASV } \\
\hline Espiritualidade Organizacional & 0,830 & 0,619 & 0,585 & 0,452 \\
\hline Características Funcionais da Empresa & 0,827 & 0,555 & 0,319 & 0,271 \\
\hline Conexão com a Empresa & 0,682 & 0,518 & 0,585 & 0,404 \\
\hline
\end{tabular}

CR > 0,7; AVE > 0,5; CR > AVE; MSV < AVE e ASV <AVE

Fonte: Autoria própria.

Mediante a análise da tabela, observa-se que, em geral, os resultados obtidos são satisfatórios. No que tange aos construtos espiritualidade organizacional e características funcionais da empresa, todos os parâmetros de validação convergente e discriminante foram alcançados. 
Contudo, observa-se que o índice confiabilidade composta do construto conexão com a empresa apresentou valor um pouco abaixo do ideal $(0,7)$. Do mesmo modo, a variância média do construto (AVE) não superou a variância quadrada compartilhada (MSV). Tais resultados indicam que as variáveis observáveis do construto conexão com a empresa apresentam semelhanças de conteúdo com as variáveis de algum outro fator da análise. Os valores supracitados podem ser visualizados na tabela 3.

Tabela 3 - Confiabilidade composta e máxima variância quadrada compartilhada dos construtos

\begin{tabular}{l|c|c|c|c}
\hline & $\mathbf{C R}$ & $\begin{array}{c}\text { Espiritualidade } \\
\text { organizacional }\end{array}$ & $\begin{array}{c}\text { Características } \\
\text { funcionais da } \\
\text { empresa }\end{array}$ & $\begin{array}{c}\text { Conexão com a } \\
\text { empresa }\end{array}$ \\
\hline Espiritualidade organizacional & 0,830 & 0,619 & & \\
\hline $\begin{array}{l}\text { Características funcionais da } \\
\text { empresa }\end{array}$ & 0,827 & 0,222 & 0,555 & 0,518 \\
\hline Conexão com a empresa & 0,682 & 0,585 & 0,319 & \\
\hline
\end{tabular}

Nota: Os valores da diagonal indicam a variância extraída e os demais correspondem à variância compartilhada (correlações ao quadrado).

Fonte: Autoria própria.

Ao se observar a correlação ao quadrado dos construtos, constata-se que o construto conexão com a empresa apresenta maior correlação com a variável latente espiritualidade organizacional $(0,585)$. Isso ocorre porque o fator conexão com a empresa é formado por uma variável advinda do construto espiritualidade organizacional (E.3) e outra que traz uma ideia fortemente relacionada à espiritualidade (DC.9). As demais relações entre construtos apresentaram valores satisfatórios.

Com base nos resultados obtidos, por meio das etapas protocolares de validação da escala, demonstrase a solidez dos construtos espiritualidade organizacional, características funcionais da empresa e conexão com a empresa, além da relevância de variáveis ligadas à espiritualidade organizacional na decisão de compra do consumidor de planos de saúde. Pode-se notar que, a partir das principais características que influenciam a decisão de compra, o construto espiritualidade organizacional se manteve coeso, apresentando, ademais, a maior percentagem de explicação na análise fatorial exploratória.

É importante salientar que, muito embora uma questão ligada ao construto tenha se dispersado e aderido em outra variável latente, tal fenômeno pode ter ocorrido devido ao fato do construto espiritualidade organizacional ainda estar sendo debatido e de conclusões definitivas sobre as dimensões que o constituem ainda não terem sido alcançadas. De todo modo, as ideias que as variáveis carregam ajudaram a corroborar a importância da espiritualidade na decisão de compra dos consumidores de plano de saúde.

Os construtos cujas variáveis relacionadas à espiritualidade organizacional ajudaram a construir foram: espiritualidade organizacional e conexão com a empresa. Os construtos carregam um ideário de transcendência dos aspectos puramente técnicos ou financeiros, apresentados pelas demais variáveis latentes da pesquisa: preço e características funcionais da empresa. A espiritualidade, então, é um aspecto importante para a cristalização de elementos fundamentais que facultam o desenvolvimento de empresas de plano de saúde, uma vez que possibilita o alcance dos objetivos organizacionais e do bem-estar, tanto de seu público interno quanto da comunidade em que está inserida (ASHMOS;DUCHON, 2000; BARCHIFONTAINE, 2007; VASCONCELOS, 2008; ULVOAS-MOAL, 2010).

\subsection{Espiritualidade interna e teste ANOVA}

Após os tratamentos descritos, foi realizada uma nova análise fatorial exploratória com todos os 233 questionários válidos para averiguar o construto espiritualidade interna. Com efeito, os indivíduos com cargas fatoriais negativas foram classificados como não espiritualizados, ao passo que os que apresentaram carga fatorial positiva foram definidos como espiritualizados.

Como esperado, as variáveis se agruparam em um único fator, apresentando bons indicadores. O fator apresentou um KMO de 0,862, um teste de esfericidade de Bartlett significante $(p=0,000)$ e uma 
variância explicada de $88,88 \%$, o que demonstra a consistência da estrutura erigida pela análise. O alpha de Cronbach do construto alcançou o valor de 0,952, indicando uma confiabilidade satisfatória (MALHOTRA, 2006). Dos pesquisados, 118 (50,60\%) pertencem ao grupo das pessoas não espiritualizadas e 115 $(49,40 \%)$ ao grupo dos indivíduos espiritualizados.

A ANOVA foi realizada com os 233 pesquisados para conhecer se realmente há diferenças significativas entre os grupos dos consumidores espiritualizados e não espiritualizados em relação aos construtos encontrados. Para realizar essa ação, foi calculada a média dos construtos, utilizando-se os construtos espiritualidade organizacional, características funcionais da empresa e conexão com a empresa.

$\mathrm{Na}$ tabela 4, a seguir, são apresentadas as médias e os desvios-padrões dos grupos de indivíduos espiritualizados e não espiritualizados.

Tabela 4 - Média e desvio padrão dos grupos e construtos da pesquisa

\begin{tabular}{|c|c|c|c|}
\hline Construtos & & Média & Desvio-Padrão \\
\hline \multirow{3}{*}{$\begin{array}{l}\text { Espiritualidade organizacional } \\
\text { Espiritualizados } \\
\text { Total }\end{array}$} & $\begin{array}{c}\text { Não } \\
\text { espiritualizados }\end{array}$ & 8,45 & 1,6002 \\
\hline & 9,07 & 1,0153 & \\
\hline & 8,75 & 1,3771 & \\
\hline \multirow{3}{*}{$\begin{array}{l}\text { Características funcionais da empresa } \\
\text { Espiritualizados } \\
\text { Total }\end{array}$} & $\begin{array}{c}\text { Não } \\
\text { espiritualizados }\end{array}$ & 9,17 & 1,1769 \\
\hline & 9,35 & 0,7178 & \\
\hline & 9,26 & 0,9796 & \\
\hline \multirow{3}{*}{$\begin{array}{l}\text { Conexão com a empresa } \\
\text { Espiritualizados } \\
\text { Total }\end{array}$} & $\begin{array}{c}\text { Não } \\
\text { espiritualizados }\end{array}$ & 7,45 & 2,1408 \\
\hline & 8,39 & 1,2292 & \\
\hline & 7,91 & 1,8107 & \\
\hline \multirow{3}{*}{$\begin{array}{l}\text { Preço } \\
\text { Espiritualizados } \\
\text { Total }\end{array}$} & $\begin{array}{c}\text { Não } \\
\text { espiritualizados }\end{array}$ & 8,25 & 1,8020 \\
\hline & 8,61 & 1,3550 & \\
\hline & 8,42 & 1,6040 & \\
\hline
\end{tabular}

Fonte: Autoria própria.

$\mathrm{Na}$ tabela 5 podem ser visualizados os resultados do teste ANOVA com os valores encontrados para cada grupo em relação aos construtos da pesquisa. Como é possível constatar, os grupos apresentaram diferença de variância ao se analisarem os construtos espiritualidade organizacional, conexão com a empresa e preço. No caso desse último, contudo, significante somente a 10\%. Quanto ao construto características funcionais da empresa, os grupos não apresentaram divergência de variância. Assim como apresentado na tabela 4, o construto é o mais importante da análise, alcançando as médias mais altas para ambos os grupos de respondentes. Uma possível explicação para a similaridade entre eles. 
Tabela 5 - ANOVA entre grupos e construtos da pesquisa

\begin{tabular}{|c|c|c|c|c|c|c|}
\hline Construtos & Grupos & $\begin{array}{l}\text { Soma dos } \\
\text { quadrados }\end{array}$ & df & $\begin{array}{l}\text { Média dos } \\
\text { quadrados }\end{array}$ & $\mathbf{F}$ & Sig. \\
\hline \multirow{3}{*}{$\begin{array}{l}\text { Média espiritualidade } \\
\text { organizacional } \\
\text { Nos grupos } \\
\text { Total }\end{array}$} & Entre Grupos & 22,833 & \multirow{3}{*}{$\begin{array}{c}1 \\
1,806\end{array}$} & \multirow[t]{3}{*}{22,833} & \multirow[t]{3}{*}{12,645} & $0,000^{* *}$ \\
\hline & 417,112 & 231 & & & & \\
\hline & 439,945 & 232 & & & & \\
\hline \multirow{3}{*}{$\begin{array}{l}\text { Média características } \\
\text { funcionais da empresa } \\
\text { Nos grupos } \\
\text { Total }\end{array}$} & Entre Grupos & 1,855 & \multirow{3}{*}{$\begin{array}{c}1 \\
0,956\end{array}$} & \multirow[t]{3}{*}{1,855} & \multirow[t]{3}{*}{1,940} & 0,165 \\
\hline & 220,801 & 231 & & & & \\
\hline & 222,655 & 232 & & & & \\
\hline \multirow{3}{*}{$\begin{array}{l}\text { Média conexão com a } \\
\text { empresa } \\
\text { Nos grupos } \\
\text { Total }\end{array}$} & Entre Grupos & 52,175 & \multirow{3}{*}{$\begin{array}{c}1 \\
3,067\end{array}$} & \multirow[t]{3}{*}{52,175} & \multirow[t]{3}{*}{17,013} & $0,000^{* *}$ \\
\hline & 708,443 & 231 & & & & \\
\hline & 760,618 & 232 & & & & \\
\hline \multirow{3}{*}{$\begin{array}{l}\text { Preço } \\
\text { Nos grupos } \\
\text { Total }\end{array}$} & Entre Grupos & 7,671 & 1 & 7,671 & 3,007 & $0,084^{*}$ \\
\hline & 589,264 & 231 & 2,551 & & & \\
\hline & 596,936 & 232 & & & & \\
\hline
\end{tabular}

* Significante a $10 \%$; ** Significante a $1 \%$.

Fonte: Autoria própria.

No que concerne ao construto espiritualidade organizacional, a divergência de variância entre os grupos apresentou valores significativos. Os respondentes espiritualizados revelaram média superior aos não espiritualizados, indicando a importância do construto, principalmente para consumidores mais preocupados com fatores imateriais relacionados à decisão de compra.

Quanto à conexão com a empresa, a disparidade de variância também apresentou diferença significante entre os grupos de respondentes. Mais uma vez, os indivíduos pertencentes ao grupo dos espiritualizados apresentaram média superior ao grupo dos não espiritualizados. O mesmo fenômeno ocorreu ao se analisar o construto preço. Embora com um intervalo de confiança menor, os indivíduos espiritualizados ponderam a variável preço de forma mais importante do que os respondentes não espiritualizados.

Deve-se enfatizar, portanto, que os indivíduos espiritualizados deram uma importância maior para todos os construtos da pesquisa, demonstrando ser uma categoria mais exigente de consumidores. Ademais, é importante ressaltar que o construto características funcionais da empresa foi pontuado como o mais importante entre ambas as categorias de respondentes, seguido pelo construto espiritualidade organizacional. $\mathrm{O}$ fator preço, portanto, ficou na terceira posição entre os construtos relacionados à decisão de compra de planos de saúde.

\section{Conclusão}

O objetivo principal do artigo - analisar a importância da espiritualidade para a decisão de compra dos consumidores de plano de saúde - foi alcançado. A consecução de tal propósito foi obtida pela criação de uma escala que relaciona os conceitos. Com efeito, obtendo-se índices satisfatórios para a validação da escala, as dimensões encontradas foram: espiritualidade organizacional; características funcionais da empresa; conexão com a empresa; e preço.

A principal contribuição da pesquisa no âmbito acadêmico reside na tentativa de se intensificar a importância da espiritualidade no contexto organizacional, construto ainda pouco estudado, principalmente no contexto nacional. Da mesma forma, este estudo demonstra a relevância da espiritualidade no que se refere, especificamente, à área de plano de saúde; uma vez que, por meio do levantamento bibliográfico, não foram encontrados estudos que relacionassem o construto a esse segmento de mercado. 
É importante que se ressaltem, ademais, os ganhos advindos da inserção da espiritualidade no ambiente organizacional. A aplicação dos valores e princípios morais que sustentam o conceito trazem benefícios que transcendem o simples ganho de eficiência laboral e organizacional. Além do aumento na solidariedade, honestidade e benevolência, que facultam o trabalho em equipe e a transparência com a qual a empresa se expõe à sociedade, há um impacto significante na forma com que o cliente percebe e valoriza a empresa ao decidir contratar um plano de saúde.

Os resultados da pesquisa demonstraram que se incentivar e orientar por valores como a ética, a responsabilidade socioambiental, a conexão e a comunicação com clientes, que perpassam a simplória e reducionista lógica financeira-mercadológica, são atitudes que influenciam a opinião pública a respeito de uma instituição. Assim, é possível asseverar que não se prescinde do cumprimento de tais ações para que um novo contexto mercadológico seja erigido, embasado em uma ideologia que destoa da perspectiva econômica tradicional.

Ademais, salienta-se que a espiritualidade é percebida e premiada não somente pelos clientes, mas pela sociedade como um todo. Por meio da espiritualidade, a empresa consegue criar um elo com todos os elementos que constituem o ambiente que a cerca, possibilitando a intensificação dos princípios que a fundamentam, bem como a cristalização de uma rede de cooperação que impulsiona a eficiência organizacional. Esse processo, que tem cooperação como motor das relações interorganizacionais, acarreta consequentemente o progresso dos valores basilares do conceito de espiritualidade.

Do mesmo modo, cabe às empresas o delineamento de uma missão em consonância com as necessidades da sociedade, fundamentando-se em objetivos que expressem e satisfaçam os interesses dos seus clientes e do corpo funcional.

A principal contribuição desta pesquisa, destarte, é auxiliar as empresas do mercado de planos de saúde a se certificarem da importância dos principais fatores que influenciam a decisão de compra nesse segmento empresarial. Como limitações do estudo salienta-se que o número de respondentes, embora esteja adequado aos parâmetros apontados por alguns autores, deve ser aumentado para que se obtenha uma amostra mais representativa dos consumidores de plano de saúde. Do mesmo modo, ressalta-se a importância de se ampliar a pesquisa para o público em geral, uma vez que esta pesquisa foi realizada somente com universitários.

A importância dos planos de saúde individuais e familiares, foco deste artigo, foi ressaltada na introdução do trabalho. Com $20 \%$ do total de contratos de planos de saúde e mais de 10 milhões de pessoas assistidas (ABRAMGE, 2014; CONSELHO FEDERAL DE MEDICINA, 2014), esse segmento de mercado dos planos de saúde é significativo e merece atenção, o que se reforça com a informação de que essa categoria é a principal responsável pelo crescimento do setor de planos de saúde $(7,4 \%)$, ficando em segundo lugar os planos coletivos empresariais $(4,5 \%)$ e registrando-se um decréscimo de $6,2 \%$ nas vendas dos planos coletivos por adesão (ABRAMGE, 2015).

Como sugestão para pesquisas futuras, sugere-se que se observe a abrangência total da escala e outros construtos relacionados ao tema, juntamente com a influência da espiritualidade na decisão de compra, consultando outros tipos de público. Do mesmo modo, indica-se a replicação do estudo em outras regiões para aferir se a espiritualidade exerce influência significativa sobre a decisão de compra em outros contextos culturais.

\section{Referências}

ASSOCIAÇÃO BRASILEIRA DE MEDICINA DE GRUPO (ABRAMGE). Cenário da Saúde. Mercado de Saúde Suplementar, [S.I.], v. 1, n. 1, p. 1-15, 2014.

ASSOCIAÇÃO BRASILEIRA DE MEDICINA DE GRUPO (ABRAMGE). Cenário da Saúde. Mercado de Saúde Suplementar,[S.I.],v. 1, n. 2, p. 1-23, 2015.

ASHMOS, D. P.; DUCHON, D. Spirituality at work: A conceptualization and measure. Journalof management inquiry, [S.I.], v. 9, n. 2, p. 134, 2000. 
BARCHIFONTAINE, C. P. Espiritualidade nas empresas. O Mundo da Saúde, São Paulo, v. 32, n. 2, p. 301-305, 2007.

BERGKVIST, L.; ROSSITER, J. R. The predictive validity of multiple-item versus single-item measures of the same constructs. Journal of Marketing Research,[S.I.],v. 44, n. 2, p. 175-184, 2007.

CAVANAGH, G. F. Spirituality for managers: Context and critique. Journal of Organizational Change Management, [S.I.], v. 12, n. 3, p. 186-199, 1999.

CHOWDHURY, R. M. M. I.; FERNANDO, M. The role of spiritual well-being and materialism in determining consumers' ethical beliefs: An empirical study with Australian consumers. Journal of Business Ethics, [S.I.], v. 113, n. 1, p. 61-79, 2013.

CHURCHILL, G. A. A paradigm for developing better measures of marketing constructs. Journal of Marketing Research, [S.I.], v. 16, n. 1, p. 64-73, 1979.

CONSELHO FEDERAL DE MEDICINA. Informações sobre a saúde suplementar no Brasil, 2015. Disponível em:<http://portal.cfm.org.br/ index.php?option=com_content\&view=article\&id=22200:informac oes-sobre-a-saude-suplementar-no-brasil\&catid=3>.Acessado em: 13 de março de 2015.

COSTA, F. J. Mensuração e Desenvolvimento de Escalas: Aplicações em Administração. Rio de Janeiro: Editora Ciência Moderna, 2011.

DOLLAHITE, D. C. Fathering, faith and spirituality. Journal of Men's Studies,[S.I.],v. 7, n. 1, p. 3-15, 1998.

DUCHON, D.; ASHMOS P. D.Nurturing the spirit at work: Impact on work unit performance. Leadership Quarterly,[S.I.], v. 16, p. 625-634, 2005.

EMMONS, R. A. Religion in the psychology of personality: An introduction. Journal of Personality, [S.I.], v. 67, n. 6, p. 874-888, 1999.

ENGEL, J. F.; BLACKWELL, R. D.; MINIARD, P. W. Consumer Behavior. Orlando: The Dryden Press, 1995.

FORNELL, C.; LARCKER, D. F. Evaluating structural equation models with unobservable variables and measurement error. Journal of Marketing Research, [S.I.],v. 18, n. 1, p. 39-50, 1981.

GARVER, M. S.; MENTZER, J. T. Logistics research methods: employing structural equation modeling to test for construct validity. Journal of Business Logistics, [S.I.], v. 20, n. 1, p. 33, 1999.

GOTSIS, G.; KORTEZI, Z. Philosophical foundations of workplace spirituality: A critical approach.

Journal of Business Ethics, [S.I.],v. 78, n. 4, p. 575-600, 2008.

HAIR, J. F.et al.Análise Multivariada de Dados.Porto Alegre: Bookman, 6ª ed., 2009.

KALE, S.Consumer spirituality and marketing.Asia-Pacific Advances in ConsumerResearch,[S.I.], v. 7 , n.1, p. 108-110, 2006.

KUMAR, V. et al. Marketing through spirituality: A case of PatanjaliYogpeeth. Procedia - Social and BehavioralSciences, [S.I.], v. 133, n.3, p. 481-490, 2014.

MALHOTRA, N. K. Pesquisa de Marketing: uma orientação aplicada. Porto Alegre: Bookman, 2006.

MILLER, W. R.; THORESEN, C. E. Spirituality, religion, and health: An emerging research field.

American psychologist, Washington, v. 58, n. 1, p. 24, 2003.

PETCHSAWANG, P.; DUCHON, D. Measuring workplace spirituality in an Asian context.

HumanResourceDevelopmentInternational, [S.I.], v. 12, n. 4, p. 459-468, 2009.

PINTO, R.Espiritualização nas Organizações: transformando valores em ações. Rio de Janeiro:

Qualitymark, 2009.

SHAW, D.; THOMSON, J. Consuming spirituality: the pleasure of uncertainty. European Journal of 
Marketing, [S.I.],v. 47, n. 3, p. 557-573, 2013.

STANDIFER, R. L.; EVANS, K. R.; DONG, B. The influence of spirituality on buyer perception within business-to-business marketing relationships: a cross-cultural exploration and comparison. Journal of Relationship Marketing, [S.I.], v. 9, n. 3, p. 132-160, 2010.

TORNSTAM, L. Late Life Transcendence: a new developmental perspective on aging. In THOMAS, L. E.; EISENHANDLER, S. A. (Eds). Religion, Belief and Spirituality in Late Life. New York: Springer, 1999, p. $178-202$.

ULVOAS-MOAL, G. Exploring the Influence of Spirituality: A New Perspective on Senior Consumers' Behavior. Advances in ConsumerResearch, [S.I.],v. 37, n.1, p. 917-919, 2010.

VASCONCELOS, A. F. Espiritualidade no ambiente de trabalho: dimensões, reflexões e desafios. São Paulo: Atlas, 2008.

VITELL, S. J. Consumer ethics research: Review, synthesis and suggestions for the future.Journalof Business Ethics, [S.I.],v. 43, n. 1, 33-47, 2003.

ZILBER, M. A.; LAZARINI, L. C. Estratégias competitivas na área da saúde no Brasil: um estudo exploratório. Revista de Administração Contemporânea, Curitiba , v. 12, n. 1, 131-154, jan./mar 2008.

ZINNBAUER B. J.; PARGAMENT, K. I. Religiousness and spirituality.In PALOUTZIAN, R. F.; PARK, C. L. (Ed). The Handbook for the Psychology of Religion. New York: The Guilford Press, 2005.

Data de Submissão: 20/5/17

Data de Aprovação: 9/4/17 